The BMJ

Cite this as: $B M J 2022 ; 376: 0147$ http://dx.doi.org/10.1136/bmj.0147 Published: 25 January 2022

\section{How do you deal with a colleague who has body odour?}

It is unpleasant to work in a confined space with someone who has personal hygiene problems.
Adele Waters hears how to approach this sensitive matter

Adele Waters

\section{There may be more to the situation than can be shared with you}

Nicola Brown, human resources and employment law expert at Pure Employment Law, says, "Poor personal hygiene can cause significant problems in the workplace. It can make the working environment unpleasant for anyone else who has to share the space. It's often the case, however, that people are unaware that they have a problem until it's brought to their attention. Frequently, poor personal hygiene or body odour is a sign of an underlying problem, be it personal or medical.

"The sensitive nature of this matter means it's best for you to speak to HR or, where appropriate, a relevant manager. Usually, their first step would be to have a word in private with the employee in question, and they would manage the situation from then on. In most cases, their intervention will resolve the matter.

"If the problem persists, however, then you may need to follow up with them. If that still doesn't work, consider raising a formal grievance with your employer about the matter not being resolved.

"Bear in mind that there may be more to the situation than the organisation is able to share with you. For example, sometimes employees can raise health or cultural matters as an explanation for their smell. If disciplinary action is taken against them they may claim the employer's actions relate to a protected characteristic-for example, disability or religion-and are therefore discriminatory. These kinds of allegations can be complex and may take time to deal with.

"Situations like this are never easy, but they do need to be dealt with. It's important to be sympathetic to the feelings of the employee while also being clear that an unpleasant working environment shouldn't be allowed to continue."

\section{Tell them yourself, don't pretend to be a messenger}

Mat Daniel, medical doctor and coach at Coaching for Doctors, says, "This matter is sensitive, so start by putting yourself in the other person's shoes, and don't make any assumptions.

"It may be that your colleague isn't aware that they have body odour or they may know but have chosen not to deal with it, in which case you'll need to be open to the possibility that there are genuine reasons why. Taking a non-judgemental attitude will create more empathy when you do have the difficult discussion.
"Whether they know or not, they're likely to be upset by the conversation so approach it sensitively from the start. If possible, make sure that you already have good rapport with the person-feedback coming from a trusted colleague will be less threatening than formal feedback from a manager.

"Tell them yourself and don't pretend to be someone else's messenger; they will feel even worse if they think the team is talking about them. Choose your language carefully-for example, having body odour is less threatening than telling someone that they smell.

"Ensure that you're in a private space when the conversation happens. Tell them that you have some sensitive personal feedback that you wish to offer. Ask, genuinely, if they're willing to receive it, and be open to walking away if they say no. If they are willing, start by telling them that you've noticed that they have body odour, ask whether they have noticed anything themselves, and be prepared to be open to the possibility that there may be circumstances that explain the problem-it may turn out that they need support. Reassure them that the body odour is in no way linked to their professional performance, and that you remain a loyal colleague."

\section{Downplay the problem to help them feel less embarrassed}

Georgina Thomas, senior solicitor at Bridge Employment Law, says, "Managing complaints by employees about colleagues, especially when concerning something sensitive like body odour or personal hygiene, can be tricky.

"Cases of poor personal hygiene require employers to act reasonably to avoid breaching contractual obligations and, in complex cultural or medical cases, employers have extra legal hurdles to clear to prevent discrimination and harassment.

"My first piece of advice is to assess the matter confidentially and carefully through management. If you are the line manager, meet your colleague to discuss the matter informally and confidentially, ideally towards the end of the working day.

"Explain you have a sensitive matter to discuss. I'd downplay the problem to help them feel less embarrassed. Be honest and kind but also be direct, don't try and tackle the problem by means of well intended hints. Ask them what may be causing the odour and how you can help. Take notes-you may need them if you need to handle the situation formally.

"If your colleague becomes defensive or angry (assuming it isn't a legally protected matter-see 
below) you may need to be firmer and make it clear you expect improvement as a reasonable instruction, giving time and space to improve and offering help.

“If the problem doesn't go away, you may need a more formal approach, setting clear standards and goals and monitoring them closely. Take legal advice at this point as getting this wrong can be costly.

"Underlying personal, health, or cultural matters may attract legal protections under the Equality Act 2010, possibly leading to discrimination claims if you treat employees less favourably because of the matter. In that case, the matter will need specific legal guidance on assessment and medical or occupational health assessments prior to any decision being made." 